\title{
Arrowroot Starch-Based Films Incorporated With a Carnauba Wax Nanoemulsion, Cellulose Nanocrystals, and Essential Oils: a New Functional Material for Food Packaging Applications
}

Josemar Gonçalves de Oliveira Filho ( $\sim$ josemar.gonsalves@hotmail.com )

Sao Paulo State University Julio de Mesquita Filho: Universidade Estadual Paulista Julio de Mesquita Filho https://orcid.org/0000-0001-9755-7128

\section{Beatriz Regina Albiero}

University of Sao Paulo: Universidade de Sao Paulo

\section{Lavínia Cipriano}

Federal University of Sao Carlos: Universidade Federal de Sao Carlos

Carmen Cris de Oliveira Nobre Bezerra

Federal University of Sao Carlos: Universidade Federal de Sao Carlos

Fernanda Campos Alencar Oldoni

Sao Paulo State University Julio de Mesquita Filho: Universidade Estadual Paulista Julio de Mesquita Filho

\section{Mariana Buranelo Egea}

Goiano Federal Institute: Instituto Federal Goiano

Henriette Monteiro Cordeiro de Azeredo

Embrapa: Empresa Brasileira de Pesquisa Agropecuaria

\section{Marcos David Ferreira}

Embrapa: Empresa Brasileira de Pesquisa Agropecuaria

\section{Research Article}

Keywords: emulsion films, nanocellulose, carnauba wax, arrowroot starch

Posted Date: March 5th, 2021

DOl: https://doi.org/10.21203/rs.3.rs-271384/v1

License: (c) (i) This work is licensed under a Creative Commons Attribution 4.0 International License. Read Full License 


\section{Abstract}

Arrowroot starch (AA)-based films incorporated with a carnauba wax nanoemulsion (CWN), cellulose nanocrystals (CNCs), and essential oils (EOs) from Mentha spicata (MEO) and Cymbopogon martinii (CEO) were produced using the casting technique and then characterized in terms of their water barrier, tensile, thermal, optical, and microstructural properties and in vitro antifungal activity against Rhizopus stolonifer and Botrytis cinerea. Whereas the incorporation of CNCs decreased the moisture content and water vapor permeability of the AA/CWN/CNC film, the additional incorporation of either EO decreased the transparency and affected the microstructure of the AA/CWN/CNC/EO nanocomposites. MEO and CEO incorporation improved the thermal stability of the films and provided excellent protection against fruit-spoiling fungi. Because of their excellent barrier properties against fungal growth, water vapor permeability, and ultraviolet and visible light, these AA/CWN/CNC/EO films have promising potential for application as active food packaging or coating materials.

\section{Introduction}

Food packaging is traditionally based on polymers of petrochemical origin, such as polypropylene, polyethylene, and polystyrene, owing to their low costs and well-established production. However, the nonbiodegradability of these materials has caused serious environmental problems. For this reason, immense efforts are being made in the research and development of biodegradable films for food packaging applications, with one new approach being the use of biopolymers extracted from food sources (Mahcene et al. 2020).

Among the various biopolymers, starch is a good raw material for the production of edible and biodegradable films because of its transparency, good gas barrier property, high availability, and low production cost (Thakur et al. 2019). Arrowroot (Maranta arundinacea), an unconventional food species native to Latin America, has a high amylose-based starch content in its rhizome. Amylose-rich starches are an interesting resource for the production of biodegradable films with good mechanical properties (Valadares et al. 2020). Although the hydrophilic nature of starch-based films makes them poor water barriers (Thakur et al. 2019), this disadvantage can be minimized through the incorporation of hydrophobic compounds, such as oils, fats, fatty acids, and waxes (e.g., carnauba wax) (Rodrigues et al. 2014; Syahida et al. 2020).

However, the addition of these compounds may create discontinuities in the film structure, negatively affecting its optical, mechanical, and barrier properties (Syahida et al. 2020; Zhang et al. 2018). In recent years, nanotechnology has been used as a new strategy for improving the properties of films (Espitia et al. 2019). For example, the incorporation of a nanoemulsion of carnauba wax into arrowroot starch (AA)based films lowered the water vapor permeability, improved the transparency and tensile strength, and smoothened the microstructure of the nanocomposites in comparison with those same features in films made with a microemulsion of the wax (8). Thus, the formulation of starch-based films incorporated with 
lipid nanoemulsions is a promising approach for the development of new film materials with improved properties.

Cellulose nanocrystals (CNCs), which are needle-like nanomaterials measuring 4-25 nm in diameter and 100-1000 nm in length (Jonoobi et al. 2015), have been proposed as a new strategy for improving the mechanical and water barrier properties of new coating or film materials, reinforcing the biopolymer matrix, and allowing the development of nanocomposite materials (Azeredo et al. 2012; Dai et al. 2020; Pereda et al. 2014). Additionally, nanomaterials have low or no cytotoxic effects in humans and can improve the stability of lipid compounds in emulsion-based systems via noncovalent physical adsorption (Hubbe et al. 2017).

Moreover, other ingredients with biological properties can be added to nanocomposite films. Indeed, nanoemulsion-based films and coatings have shown promise for transporting natural bioactive compounds, such as essential oils (EOs) (Aswathanarayan and Vittal 2019), which are natural antimicrobials and antioxidants valued for their safe, biodegradable, and non-toxic properties (Abdollahi et al. 2013; Atarés and Chiralt 2016; Sánchez-González et al. 2011).

The objective of this study was to develop a novel functional material for food packaging applications. To this end, we fabricated films based on an AA matrix, into which a carnauba wax nanoemulsion (CWN) (to improve the water vapor barrier property), CNCs (to enhance the tensile properties), and EOs from a green mint plant and palmarosa grass (to provide antifungal properties) were incorporated.

Characterization of the $\mathrm{AA} / \mathrm{CWN} / \mathrm{CNC} / \mathrm{EO}$ nanocomposite properties revealed the films to be promising materials for the primary packaging or coating of a variety of perishable food products, such as fresh fruits, vegetables, breads, and cheeses.

\section{Materials And Methods}

\subsection{Materials}

The AA used as the film-forming matrix contained $13.24 \%$ water, $86.09 \%$ carbohydrate, $0.30 \%$ ash, $0.28 \%$ protein, and $0.10 \%$ fat (as previously described by Oliveira Filho et al. (2020a)). Glycerol ( $99.5 \%$ purity; CAS No.: 56-81-5; Alphatec Química Fina, Santo André, SP, Brazil) was used as the plasticizer. The CNCs, which were obtained from Bionano (São Carlos, SP, Brazil), had an average length of $384 \pm 102 \mathrm{~nm}$ and diameter of $15 \pm 2 \mathrm{~nm}$ (resulting in an aspect ratio of approximately 25.6) and a zeta potential value of $22.62 \mathrm{mV}$. Carnauba wax type I (99\% purity; CAS No.: 8015-86-9) was provided by Pontes Indústria de Cera (Parnaíba, PI, Brazil). Palm oleic acid (99\% purity; CAS No.: 67701-08-0), dimethylpolysiloxane (99\% purity; CAS No.: 63148-62-9), and ammonium hydroxide (99\% purity; CAS No.:1336-21-6) were purchased from Sigma-Aldrich Chemical Co. (St. Louis, MO, USA). The EO of palmarosa grass (Cymbopogon martinii) (CEO) was purchased from Laszlo Aromaterapia (Belo Horizonte, Brazil), whereas that of green mint (Mentha spicata) (MEO) was purchased from Ferquima Ind. e Com. Ltda (Vargem Grande Paulista, SP, Brazil). Using gas chromatography and mass spectrometry (QP-5000, Shimadzu, Columbia, MD, USA), 
13 chemical compounds were identified in CEO (total of 98.55\%), including geraniol (83.82\%), geranyl acetate $(7.49 \%)$, linalool $(2.48 \%)$, and caryophyllene (1.33\%), whereas 18 chemical compounds were identified in MEO (total of $96.99 \%)$, including menthol (45.37\%), menthone $(20.13 \%)$, isomenthone (16.94\%), menthyl acetate (3.81\%), pulegone (1.89\%), a-terpinene (1.88\%), isopulegol (1.83\%), neoisomenthol (1.19\%), and a-terpineol (1.08\%) (unpublished data). The fungi used for the antifungal tests were Rhizopus stolonifer strain CCT 0276 and Botrytis cinerea strain CCT 1252 (Andre Tosello Foundation, Campinas, SP, Brazil). All reagents used in this work were of analytical grade.

\subsection{Carnauba wax nanoemulsion}

The CWN (droplet size: $39.3 \pm 0.7 \mathrm{~nm}$; zeta potential: $-40.32 \pm 1.0 \mathrm{mV}$ ) was prepared according to the method described by Hagenmaier and Baker (1994) and adapted by Campos et al. (2019).

Characterization of the nanoemulsion was carried out as previously described in another study by our group (Oliveira Filho et al. 2020a).

\subsection{Film preparation}

To prepare the films, CNCs and AA (5:95, w/w) were first dissolved in water, under agitation with a magnetic stirrer (150 rpm) in a thermostatic bath (TE-2005, TECNAL, Piracicaba, Brazil) at $85 \pm 2^{\circ} \mathrm{C}$ for 5 min, to produce a $2 \%(\mathrm{w} / \mathrm{w})$ aqueous solution. Then, the CWN ( $15 \%$ on a dry starch basis) was added to the aqueous mixture (Oliveira Filho et al. 2020a) and the suspension was homogenized. Thereafter, glycerol was added as the plasticizer to a level of $0.17 \mathrm{~mL} / \mathrm{g}$ AA.

After the dispersions had been cooled to $40^{\circ} \mathrm{C}, \mathrm{MEO}$ or CEO was added at the concentrations of $0.1 \%$, $0.2 \%$, and $0.3 \%(\mathrm{v} / \mathrm{v})$ and the mixtures were stirred on a high-speed mixer (UltraTurrax T25, IKA Werke $\mathrm{GmbH} \& \mathrm{Co}$, Staufen, Germany) for $5 \mathrm{~min}$. The film-forming dispersions $(25 \mathrm{~mL})$ were cast on Petri dishes $(\varnothing 12 \mathrm{~cm})$ and dried at $35^{\circ} \mathrm{C}$ for $24 \mathrm{~h}$, following which the resultant films were detached from the plates and conditioned at ambient temperature (relative humidity (RH): $50 \%$ ) for $48 \mathrm{~h}$ before analysis.

\subsection{Film characterization}

\subsubsection{Thickness, moisture content, and water solubility}

The film thickness and moisture content were measured using the methods described by Oliveira Filho et al. (2020). The solubility of the films was measured as described by Kavoosi et al. (2014).

\subsubsection{Water vapor permeability}

The water vapor permeability (WVP) of the films was determined using the gravimetric method (E96/E96M-16, 2016). In brief, the films were sealed in permeation cups (diameter: $35 \mathrm{~mm}$ ) containing 6 $\mathrm{mL}$ of distilled water and placed in an air circulation oven (Solab SL-102, Piracicaba, SP, Brazil) at $40^{\circ} \mathrm{C}$ with activated silica gel (RH: $0 \%)$. The cups were then weighed at least 10 times over the next $34 \mathrm{~h}$. The WVP $\left(\mathrm{g} \cdot \mathrm{mm} \bullet \mathrm{h}^{-1} \cdot \mathrm{cm}^{-2} \cdot \mathrm{Pa}^{-1}\right)$ was calculated according to Eq. (1): 
$W V P=\frac{m}{t} \cdot \frac{x}{A \cdot \Delta p}$

where $m$ is the water loss from the permeation cup, $A$ is the film sample area, $t$ is the time of analysis, and $\Delta p$ is the difference in water vapor pressure between the inside and outside of the cup.

\subsubsection{Tensile properties}

The tensile properties of $50 \mathrm{~mm} \times 10 \mathrm{~mm}$ film specimens $(n=10)$ was determined using the D882-12 method (ASTM, 2012). This analysis was performed using the TA.XTplus texture analyzer (Stable Micro Systems, Surrey, UK) equipped with A/TG Tensile Grips and a $50 \mathrm{~N}$ load cell, with an initial grip separation of $20 \mathrm{~mm}$ and a crosshead speed of $80 \mathrm{~mm} / \mathrm{min}$.

\subsubsection{Thermogravimetric analysis}

Thermal degradation profiles were obtained by thermogravimetric analysis (TGA), using a TGA Q500 analyzer (TA Instruments, New Castle, DE, USA) with heating from 10 to $600^{\circ} \mathrm{C}$ at a rate of $10^{\circ} \mathrm{C} / \mathrm{min}$ and a nitrogen flow rate of $40 \mathrm{~mL} / \mathrm{min}$. The percentage weight loss (\%) and the first derivative of the TGA curve $\left(\% /{ }^{\circ} \mathrm{C}\right)$ were determined as a function of temperature.

\subsubsection{Optical properties}

The hue angle $\left(h^{\circ}\right)$, chroma $\left(C^{\star}\right)$, and total color difference $\left(\Delta E^{\star}\right)$ were calculated using Eqs. (2) and (3), respectively, on the basis of the $L^{*}, a^{*}$, and $b^{\star}$ values (CIELAB color system) determined using a colorimeter (HunterLab, Reston, VA, USA).

$$
\begin{aligned}
& h^{0}=\tan ^{-1}\left(\frac{b^{*}}{a^{*}}\right) \\
& C^{*}=\left(\left(a^{*}\right)^{2}+\left(b^{*}\right)^{2}\right)^{1 / 2}
\end{aligned}
$$

The film opacity, which was based on the fractional transmittance at $600 \mathrm{~nm}\left(T_{600}\right)$ and film thickness $(x$, mm), was calculated using Eq. (4) (Hamdi et al. 2019).

Opacity $=\frac{-\log \left(T_{600}\right)}{x}$

An ultraviolet-visible (UV-Vis) spectrophotometer (Shimadzu 1600, Portland, OR, USA) was used to measure the optical barrier properties of the film against UV and visible light, with scanning carried out between 250 and $800 \mathrm{~nm}$.

\subsubsection{Scanning electron microscopy}

A scanning electron microscope (JEOL-JSM 6510 model, Jeol, Tokyo, Japan), set at an acceleration voltage of $5 \mathrm{kV}$, was used to evaluate the microstructure of the films, as described previously (Oliveira Filho et al. 2020a). 


\subsubsection{In vitro antifungal activity}

The antifungal activity of the films (diameter: $10 \mathrm{~mm}$ ) against $R$. stolonifer and $B$. cinerea was evaluated in vitro using the method described by Oliveira Filho et al. (2019). In brief, $100 \mu \mathrm{L}$ of fungal spore suspension (adjusted to $10^{5} \mathrm{spores} / \mathrm{mL}$ ) was cultured on potato dextrose agar plates. The sample films were then placed over the fungal mat on the agar surface and the plates were incubated at $25^{\circ} \mathrm{C}$ for $72 \mathrm{~h}$. The result was expressed as the diameter of the zone of inhibition measured with a caliper.

\subsection{Statistical analysis}

The results are expressed as the average of three replicates (with triplicate analyses for each repetition) \pm standard deviation. The data were analyzed using one-way analysis of variance followed by the Tukey post hoc test, with statistical significance of differences set at $p<0.05$.

\section{Results And Discussion}

\subsection{Physical properties of the films}

Table 1 shows the water-related properties of the films. The moisture contents varied from $7.03-7.89 \%$, with no significant difference arising from the incorporation of the CNCs, MEO, and CEO. As EOs are hydrophobic in nature, it was expected that the moisture content of the films would be reduced. However, this was not observed in the present work, probably as a result of the low concentrations of EOs tested. 
Table 1

Water-related properties of arrowroot starch-based films incorporated with a carnauba wax nanoemulsion, cellulose nanocrystals, and essential oils

\begin{tabular}{|c|c|c|c|}
\hline Film & Moisture content (\%) & Solubility (\%) & WVP $\left(10^{-7} \mathrm{~g} \mathrm{H}_{2} \mathrm{O} \cdot \mathrm{m}^{-1} \cdot \mathrm{h}^{-1} \cdot \mathrm{Pa}^{-1}\right)$ \\
\hline $\mathrm{AA} / \mathrm{CWN}$ & $7.89 \pm 1.88$ & $26.41 \pm 2.93^{a}$ & $3.98 \pm 0.25^{\mathrm{a}}$ \\
\hline $\mathrm{AA} / \mathrm{CWN} / \mathrm{CNC}$ & $7.42 \pm 1.86$ & $18.74 \pm 2.33^{b}$ & $3.21 \pm 0.12^{b}$ \\
\hline $\mathrm{AA} / \mathrm{CWN} / \mathrm{CNC} / \mathrm{MEO} 1^{*}$ & $7.03 \pm 0.91$ & $16.62 \pm 2.61^{\mathrm{b}}$ & $3.28 \pm 0.15^{b}$ \\
\hline AA/CWN/CNC/MEO2 & $7.26 \pm 1.16$ & $14.23 \pm 3.41^{\mathrm{bc}}$ & $3.15 \pm 0.18^{b}$ \\
\hline AA/CWN/CNC/MEO3 & $7.45 \pm 1.45$ & $12.10 \pm 3.44^{\mathrm{c}}$ & $2.92 \pm 0.60^{b}$ \\
\hline $\mathrm{AA} / \mathrm{CWN} / \mathrm{CNC} / \mathrm{CEO} 1$ & $7.09 \pm 1.71$ & $17.45 \pm 2.43^{b}$ & $3.11 \pm 0.26^{b}$ \\
\hline $\mathrm{AA} / \mathrm{CWN} / \mathrm{CNC} / \mathrm{CEO} 2$ & $7.87 \pm 2.57$ & $14.92 \pm 1.14^{\mathrm{bc}}$ & $3.06 \pm 0.38^{b}$ \\
\hline AA/CWN/CNC/CEO3 & $7.54 \pm 0.70$ & $12.60 \pm 1.23^{\mathrm{c}}$ & $2.97 \pm 0.20^{b}$ \\
\hline \multicolumn{4}{|c|}{$\begin{array}{l}\text { AA: arrowroot starch; CWN: carnauba wax nanoemulsion; CNC, cellulose nanocrystals; MEO: Mentha } \\
\text { spica essential oil; CEO: Cymbopogon martini essential oil; WVP: water vapor permeability. }\end{array}$} \\
\hline \multicolumn{4}{|c|}{$\begin{array}{l}\text { *Essential oils were added at the concentrations of } 0.1 \% \text { (MEO1 or CEO1), } 0.2 \% \text { (MEO2 or CEO2), or } \\
0.3 \% \text { (MEO3 or CEO3). }\end{array}$} \\
\hline
\end{tabular}

The solubility of the films in water varied from $12.1-26.4 \%$, decreasing significantly with the addition of CNCs and increasing concentrations of either of the EOs. The reduction in water solubility of the AAbased films following the incorporation of CNCs was a result of the formation of a three-dimensional (3D) cellulose network through hydrogen bonding between the starch and CNC molecules. Threedimensional networks reduce the solubility of biopolymers, reinforcing the structure and restricting the interactions between the polymer and water molecules (Noshirvani et al. 2018).

The reduction in water solubility of the films by the addition of the EOs was probably due to the hydrophobic nature of these molecules and their low affinity to water molecules (Ma and Wang 2016). The same observation has been reported for starch films incorporated with Syzygium aromaticum EO (Sousa et al. 2019) and chitosan films incorporated with Citrus limonia EO (Oliveira Filho et al. 2020b).

The addition of CNCs to the AA/CWN film reduced its WVP (from 3.98 to $3.2110^{-7} \mathrm{~g} \mathrm{H}_{2} \mathrm{O} \cdot \mathrm{m}^{-1} \cdot \mathrm{h}^{-1} \cdot \mathrm{Pa}^{-}$ 1), similar to results reported in the literature (Abdollahi et al. 2013; Pereda et al. 2014; Sogut 2020). According to El Miri et al. (2015), CNCs limit the mobility of water molecules through the film matrix, resulting in a reduction in the WVP of the nanocomposite film. 
The incorporation of the various concentrations of CEO or MEO did not alter the WVP of the films. This was similar to the results reported for whey protein films incorporated with oregano EO (Zinoviadou et al. 2009) and AA-based films incorporated with Piper aduncum EO (Valadares et al. 2020).

The addition of EOs was expected to reduce the WVP of the films owing to the hydrophobic nature of the oils, as previously observed for the water solubility property (Table 1). However, because WVP is a function of both solubility and diffusivity (Santos et al. 2014), the lack of a significant variation in the WVP may be due to a concomitant increase in water molecule diffusivity resulting from discontinuities in the matrix caused by the incorporated EO molecules (as shown by the scanning electron micrographs discussed below).

\subsection{Tensile properties of the films}

The film thickness increased significantly with the addition of CNCs, CEO, and MEO, similar to the results reported for films composed of whey protein isolate, CNCs, and bergamot EO (Sogut 2020) and those made up of chitosan, CNCs, and palm oil (Pereda et al. 2014). The increase in thickness of the films may be related to the increase in the amount of solids present in the nanocomposites (de Souza Coelho et al. 2020), with differences in homogeneity within the biopolymer matrices, and could also be due to interactions between the components used in the formulation of the nanocomposites (Sogut 2020).

The stress properties of the films are listed in Table 2. The incorporation of CNCs increased the tensile strength of the AA/CWN film from 3.0 to $5.3 \mathrm{MPa}$. This increase can be due to interactions between the CNCs and starch molecules and the reinforcement effect from voltage transference at the CNC-starch interface (de Mesquita et al. 2010; Khan et al. 2012). These interactions strengthen the 3D network of the nanocomposite film by creating nanofillers, which improve the mechanical properties of the film and limit the movement of the biopolymer chains (Jouyandeh et al. 2019). 
Table 2

Tensile properties and thermal properties of arrowroot starch-based films incorporated with a carnauba wax nanoemulsion, cellulose nanocrystals, and essential oils

\begin{tabular}{|c|c|c|c|c|c|}
\hline Film & $\begin{array}{l}\text { Thickness } \\
(\mathrm{mm})\end{array}$ & $\begin{array}{l}\text { Tensile strength } \\
\text { (MPa) }\end{array}$ & $\begin{array}{l}\text { Elongation at } \\
\text { break (\%) }\end{array}$ & $\begin{array}{l}T_{\text {onset }} \\
\left({ }^{\circ} \mathrm{C}\right)\end{array}$ & $\begin{array}{l}T_{\max } \\
\left({ }^{\circ} \mathrm{C}\right)\end{array}$ \\
\hline $\mathrm{AA} / \mathrm{CWN}$ & $\begin{array}{l}0.134 \pm \\
0.022^{c}\end{array}$ & $3.00 \pm 0.60^{c}$ & $247.5 \pm 32.8^{a}$ & 272.5 & 314.3 \\
\hline AA/CWN/CNC & $\begin{array}{l}0.147 \pm \\
0.310^{\mathrm{b}}\end{array}$ & $5.30 \pm 0.68^{a}$ & $125.7 \pm 42.1^{\mathrm{b}}$ & 271.8 & 313.4 \\
\hline $\mathrm{AA} / \mathrm{CWN} / \mathrm{CNC} / \mathrm{MEO} 1$ & $\begin{array}{l}0.166 \pm \\
0.040^{\mathrm{a}}\end{array}$ & $4.25 \pm 0.40^{b}$ & $123.6 \pm 39.9^{b}$ & 276.9 & 316.4 \\
\hline $\mathrm{AA} / \mathrm{CWN} / \mathrm{CNC} / \mathrm{MEO} 2$ & $\begin{array}{l}0.182 \pm \\
0.140^{a}\end{array}$ & $4.17 \pm 0.53^{b}$ & $122.5 \pm 23.1^{b}$ & 280.9 & 317.5 \\
\hline $\mathrm{AA} / \mathrm{CWN} / \mathrm{CNC} / \mathrm{MEO} 3$ & $\begin{array}{l}0.188 \pm \\
0.007^{a}\end{array}$ & $4.06 \pm 0.35^{b}$ & $117.3 \pm 47.7^{b}$ & 293.1 & 317.8 \\
\hline $\mathrm{AA} / \mathrm{CWN} / \mathrm{CNC} / \mathrm{CEO} 1$ & $\begin{array}{l}0.168 \pm \\
0.017^{a}\end{array}$ & $4.28 \pm 0.49^{b}$ & $133.2 \pm 61.9^{b}$ & 275.8 & 315.8 \\
\hline $\mathrm{AA} / \mathrm{CWN} / \mathrm{CNC} / \mathrm{CEO} 2$ & $\begin{array}{l}0.162 \pm \\
0.034^{a}\end{array}$ & $4.07 \pm 0.29^{b}$ & $118.1 \pm 39.3^{b}$ & 278.9 & 316.4 \\
\hline $\mathrm{AA} / \mathrm{CWN} / \mathrm{CNC} / \mathrm{CEO} 3$ & $\begin{array}{l}0.173 \pm \\
0.006^{a}\end{array}$ & $4.23 \pm 0.69^{b}$ & $106.7 \pm 7.73^{b}$ & 286.8 & 317.3 \\
\hline
\end{tabular}

AA: arrowroot starch; CWN: carnauba wax nanoemulsion; CNC, cellulose nanocrystals; MEO: Mentha spica essential oil; CEO: Cymbopogon martini essential oil; $T_{\text {onset }}$ : starting decomposition temperature; $T_{\text {max }}$ : maximum decomposition temperature.

*Essential oils were added at the concentrations of $0.1 \%$ (MEO1 or CEO1), $0.2 \%$ (MEO2 or CEO2), or $0.3 \%$ (MEO3 or CEO3).

Values of thickness, tensile strength, and elongation at break in the same column followed by at least one common letter are not significantly different according to the Tukey test $(p<0.05)$.

The tensile strength of the films with EOs incorporated was lower than that of the AA/CWN/CNC film. However, all films were superior in tensile strength to the control film (AA/CWN without CNCs and EOs). The changes in the mechanical properties were likely due to the presence of discontinuities in the polymer matrix caused by the EO molecules (Atarés and Chiralt 2016), corroborating the film structures seen in the scanning electron micrographs and the theory of an increase in diffusivity as being responsible for the non-reduction in WVP (Table 1). Thus, EOs increase the extensibility, flexibility, and mobility of films and decrease their cohesive strength (Mahcene et al. 2020). Whereas the elongation at break was significantly reduced from $247-125.7 \%$ with the addition of CNCs, it was not affected by the addition of EOs. The 
CNC-mediated increase in tensile strength and reduction in elongation at break of the films have also been reported by other authors (Dai et al. 2020; de Souza Coelho et al. 2020; Yadav et al. 2016).

\subsection{Thermogravimetric analysis}

Figure 1 shows the TGA curves and their first derivatives. The starting and maximum decomposition temperatures ( $T_{\text {onset }}$ and $T_{\text {max }}$ ) are shown in Table 2. Weight loss of the samples occurred in three major stages. The first stage occurred during the temperature range of $25-250^{\circ} \mathrm{C}$ and was related to the evaporation of water molecules $\left(52-92^{\circ} \mathrm{C}\right)$, glycerol $\left(200-250^{\circ} \mathrm{C}\right)$, and other volatile low-molecular-weight components. The second stage occurred between 270 and $350^{\circ} \mathrm{C}$ and was related to the thermal degradation of starch and CNCs, which occur at similar temperatures (Rico et al. 2016). The last stage occurred from 350 to $490^{\circ} \mathrm{C}$ (Freitas et al. 2016; Milanovic 2010) and was caused by the degradation of CWN and thermally stable compounds present in the EOs (Alizadeh et al. 2017; Sousa et al. 2019).

The films with MEO and CEO incorporated showed higher $T_{\max }$ values than the other films, indicating that the addition of these oils had improved the thermal stability of the nanocomposites (Table 2). These results were corroborated by other studies that showed that the improvement in thermal properties led to the higher homogeneity observed in the biopolymer matrix (Noshirvani et al. 2017; Sousa et al. 2019).

\subsection{Optical properties}

The optical properties of the films are listed in Table 3. The incorporation of EOs and CNCs did not change the $L^{*}$ parameter (luminosity) of the films. Moreover, the hue values ranged from $89.34^{\circ}$ to $90.30^{\circ}$ (between red and yellow), indicating that the films were yellow in color (Table 3). 
Table 3

Color attributes and opacity of arrowroot starch-based films incorporated with a carnauba wax nanoemulsion, cellulose nanocrystals, and essential oils

\begin{tabular}{|lllll|}
\hline Film & $L^{*}$ & $\boldsymbol{h}^{\circ}$ & $C^{*}$ & Opacity \\
\hline AA/CWN & $80.49 \pm 0.99$ & $89.88 \pm 0.67$ & $16.96 \pm 1.85^{\mathrm{a}}$ & $1.22 \pm 0.01^{\mathrm{h}}$ \\
\hline AA/CWN/CNC & $81.89 \pm 0.27$ & $89.53 \pm 0.59$ & $13.75 \pm 0.22^{\mathrm{b}}$ & $2.01 \pm 0.03^{\mathrm{g}}$ \\
\hline AA/CWN/CNC/MEO1 & $81.03 \pm 0.91$ & $89.52 \pm 0.31$ & $14.32 \pm 2.09^{\mathrm{b}}$ & $2.54 \pm 0.02^{\mathrm{d}}$ \\
\hline AA/CWN/CNC/MEO2 & $81.53 \pm 0.83$ & $90.11 \pm 0.46$ & $15.15 \pm 0.76^{\mathrm{a}}$ & $2.63 \pm 0.02^{\mathrm{c}}$ \\
\hline AA/CWN/CNC/MEO3 & $81.31 \pm 0.22$ & $89.34 \pm 0.19$ & $16.46 \pm 0.20^{\mathrm{a}}$ & $2.70 \pm 0.01^{\mathrm{b}}$ \\
\hline AA/CWN/CNC/CEO1 & $81.92 \pm 0.60$ & $90.23 \pm 0.41$ & $13.74 \pm 1.63^{\mathrm{b}}$ & $2.27 \pm 0.02^{\mathrm{f}}$ \\
\hline AA/CWN/CNC/CEO2 & $81.58 \pm 0.34$ & $90.21 \pm 0.46$ & $15.91 \pm 1.31^{\mathrm{a}}$ & $2.45 \pm 0.03^{\mathrm{e}}$ \\
\hline AA/CWN/CNC/CEO3 & $81.58 \pm 0.28$ & $90.30 \pm 0.25$ & $16.07 \pm 0.65^{\mathrm{a}}$ & $2.99 \pm 0.01^{\mathrm{a}}$ \\
\hline $\begin{array}{l}\text { AA: arrowroot starch; CWN: carnauba wax nanoemulsion; CNC, cellulose nanocrystals; MEO: } \text { Mentha } \\
\text { spica essential oil; CEO: Cymbopogon martini essential oil; } L^{*} \text { : luminosity; } h^{\circ} \text { : hue angle; } C^{*} \text { : chroma. }\end{array}$ \\
\hline $\begin{array}{l}\text { *Essential oils were added at the concentrations of } 0.1 \% \text { (MEO1 or CEO1), } 0.2 \% \text { (MEO2 or CEO2), or } \\
\text { 0.3\% (MEO3 or CEO3). }\end{array}$ \\
\hline $\begin{array}{l}\text { Values in the same column followed by at least one common letter (or not followed by any letters) are } \\
\text { not significantly different according to the Tukey test ( } \mathrm{p}<0.05 \text { ). }\end{array}$ \\
\hline
\end{tabular}

The $C^{\star}$ value decreased with the addition of CNCs, indicating that the nanocrystals lowered the color intensity of the films. By contrast, the value increased with the addition of $0.2 \%$ and $0.3 \%$ EOs, indicating that the oils made the film coloring more intense. Similar phenomena have been reported for agar films (Shankar et al. 2015) and starch films (de Souza Coelho et al. 2020). In another study, the yellowish coloration of corn and wheat starch films was attributed to the lemon EO added (Song et al. 2018).

The addition of CWN, CNCs, and EOs decreased the transparency of the AA-based films. The opacity values increased from the AA/CWN film to the AA/CWN/CNC/MEO3 and AA/CWN/CNC/CEO3 films (1.22 to 2.70 and 2.99, respectively). This increase may be due to the strong interaction between the CNCs and the starch matrix as well as light scattering by the nanocrystals (Li et al. 2018).

The increased opacity could also be due to the hinderance of light passage through the film as a result of CNC accumulation within the matrix (Abdollahi et al. 2013), as evidenced by the CNC aggregates observed in the scanning electron micrographs (Fig. 2). Similar results have been reported by other authors (de Souza Coelho et al. 2020; Thomas et al. 2020). Meanwhile, the decrease in film transparency caused by the addition of EOs was probably due to the dispersion of light by the oil droplets in the film matrix, as previously described for other films (Oliveira Filho et al. 2019; Sousa et al. 2019). 
Figure 3 shows the light transmission rate of the films. All of the fabricated films were found to be strong barriers against UV light (200-350 nm) not exceeding $0.1 \%$; that is, they provided a $100 \%$ barrier to UV light. In the visible light region $(380-780 \mathrm{~nm})$, the light transmission rate of the control film (AA/CWN) was $24.0-65.4 \%$, but this decreased to a range of $26.0-55.9 \%$ in the AA/CWN/CNC film. The addition of EOs also caused a slight reduction in light transmittance rates compared with that of the AA/CWN/CNC film (Fig. 3). The best light barrier performance was observed for films incorporated with CNCs and EOs at the highest concentration (0.3\%), which was due to the increased opacity (reported in Table 3).

Reductions in the UV-Vis light transmission rate have also been observed for chitosan films incorporated with Citrus limonia EO (Oliveira Filho et al. 2020b) and potato starch films incorporated with CNCs (Oliveira et al. 2017). Therefore, AA/CWN/CNC films with MEO or CEO can be used as food packaging materials, as they have excellent light barrier function.

\subsection{Characterization of the film microstructures}

Figure 2 shows the surface and cross-sectional microstructures of the AA-based films containing CWN, reinforced with CNCs, and supplemented with MEO or CEO. The AA/CWN film had a dense and regular surface with some lipid clusters present. In the film containing CNCs, the surface was rougher and more opaque, which was attributed to the nanocrystal aggregates, as observed in other studies on starch films containing CNCs (Johar and Ahmad 2012; Silva et al. 2019). None of the films had obvious cracks or discontinuities in their microstructures, and the addition of CNCs positively impacted the traction and barrier properties of the films (Tables 1-3).

As shown in Fig. 2, compared with the AA/CWN/CNC film, the films with EOs had lower amounts of CNC aggregates and regular and compact structures, probably as a result of the uniform distribution of the droplets within the emulsion and good compatibility between the matrices. These characteristics indicated that the emulsion was stable and there was no phase separation or droplet aggregation during the preparation and drying of the films. This may have been due to interactions between the CNCs and EOs that electrostatically stabilized the oil droplets, giving rise to Pickering emulsions (Zhang et al. 2017; Zhou et al. 2018).

With higher concentrations of EOs in the films, the microstructure of the cross-sections was slightly heterogeneous and less compact, with some holes in the films (especially with $0.3 \% \mathrm{EO}$, as a result of the oil droplets (Pastor et al. 2013; Zhou et al. 2018)). The characteristics of oil droplets in a Pickering emulsion can affect the immobilization of the emulsion (Ribeiro-Santos et al. 2017). Overall, the findings of the film microstructure corroborated the results previously described for the properties that were improved with the addition of CNCs and EOs.

\subsection{Antifungal activity}

Table 4 shows the antifungal activities of the films against $R$. stolonifer and $B$. cinerea. As expected, the $\mathrm{AA} / \mathrm{CWN}$ and $\mathrm{AA} / \mathrm{CWN} / \mathrm{CNC}$ films did not show antifungal activity against the two fungi studied, 
corroborating previous results obtained with films based on starch, waxes, and nanocellulose (Ochoa et al. 2017; Raigond et al. 2019; Salmieri et al. 2014).

Table 4

Antifungal activity of arrowroot-based films incorporated with a carnauba wax nanoemulsion, cellulose nanocrystals, and essential oils

\begin{tabular}{|c|c|c|}
\hline \multirow[t]{2}{*}{ Film } & \multicolumn{2}{|c|}{ Diameter of inhibition zone (mm) } \\
\hline & Rhizopus stolonifer & Botrytis cinerea \\
\hline $\mathrm{AA} / \mathrm{CWN}$ & $0.0 \pm 0.0^{\mathrm{e}}$ & $0.0 \pm 0.0^{f}$ \\
\hline $\mathrm{AA} / \mathrm{CWN} / \mathrm{CNC}$ & $0.0 \pm 0.0^{\mathrm{e}}$ & $0.0 \pm 0.0^{f}$ \\
\hline $\mathrm{AA} / \mathrm{CWN} / \mathrm{CNC} / \mathrm{MEO} 1$ & $16.0 \pm 1.0^{d}$ & $19.0 \pm 0.7^{e}$ \\
\hline $\mathrm{AA} / \mathrm{CWN} / \mathrm{CNC} / \mathrm{MEO} 2$ & $20.8 \pm 1.1^{c}$ & $25.9 \pm 2.0^{d}$ \\
\hline $\mathrm{AA} / \mathrm{CWN} / \mathrm{CNC} / \mathrm{MEO} 3$ & $25.2 \pm 2.0^{\mathrm{b}}$ & $33.7 \pm 1.6^{\mathrm{b}}$ \\
\hline $\mathrm{AA} / \mathrm{CWN} / \mathrm{CNC} / \mathrm{CEO} 1$ & $18.7 \pm 0.7^{c}$ & $24.3 \pm 0.8^{d}$ \\
\hline $\mathrm{AA} / \mathrm{CWN} / \mathrm{CNC} / \mathrm{CEO} 2$ & $24.1 \pm 1.6^{b}$ & $30.4 \pm 0.6^{c}$ \\
\hline $\mathrm{AA} / \mathrm{CWN} / \mathrm{CNC} / \mathrm{CEO} 3$ & $29.8 \pm 0.8^{a}$ & $36.3 \pm 0.7^{a}$ \\
\hline \multicolumn{3}{|c|}{$\begin{array}{l}\text { AA: arrowroot starch; CWN: carnauba wax nanoemulsion; CNC, cellulose nanocrystals; MEO: Mentha } \\
\text { spica essential oil; CEO: Cymbopogon martini essential oil. }\end{array}$} \\
\hline \multicolumn{3}{|c|}{$\begin{array}{l}\text { *Essential oils were added at the concentrations of } 0.1 \% \text { (MEO1 or CEO1), } 0.2 \% \text { (MEO2 or CEO2), or } \\
0.3 \% \text { (MEO3 or CEO3). }\end{array}$} \\
\hline
\end{tabular}

By contast, the films with EOs incorporated showed obvious antifungal activity that was directly proportional to the EO concentration used. The diameters of the inhibition zones against $R$. stolonifer increased from 16.0 to $25.2 \mathrm{~mm}$ for films with MEO and from 18.7 to $29.8 \mathrm{~mm}$ for films with CEO. Those against $B$. cinerea increased from 19.0 to $33.7 \mathrm{~mm}$ for films with MEO and from 24.3 to $29.8 \mathrm{~mm}$ for films with CEO. Thus, $B$. cinerea was more sensitive than $R$. stolonifer to the EOs studied. The antifungal effect of MEO is related to its chemical composition, mainly of carvone, which has high antimicrobial activity (Soković et al. 2009). By contrast, the antifungal activity of CEO is related to the synergistic effects of its major compounds: geraniol, linalool, neral, and mirceno (da Rocha Neto et al. 2019). Taken together, these results confirmed that MEO and CEO act as antifungal agents. Therefore, these EOs in combination with a film composed of $\mathrm{AA}, \mathrm{CWN}$, and CNCs provide a functional film material.

\section{Conclusions}


The incorporation of CNCs into an AA-based matrix increased the thickness and tensile strength and decreased the WVP of the AA/CWN/CNC film. Furthermore, the addition of CNCs with or without EOs decreased the transparency of the films and improved their visible light barrier property. Additionally, the incorporation of EOs improved the thermal stability of the films. The microstructure of the films was affected by the CNCs, becoming rougher and more opaque. The addition of EOs provided the films with excellent antifungal activity against post-harvest fruit-spoiling fungi. Overall, films composed of $A A, C W N$, CNCs, and MEO or CEO were excellent barriers against WVP, UV light, and fungal growth. Thus, the $\mathrm{AA} / \mathrm{CWN} / \mathrm{CNC} / \mathrm{MEO}$ and $\mathrm{AA} / \mathrm{CWN} / \mathrm{CNC} / \mathrm{CEO}$ nanocomposite films represent novel materials with potential application as active packaging materials or coatings for fresh fruits and vegetables as well as for other food products that are easily spoiled by surface fungal growth, such as breads and cheeses.

\section{Declarations}

\section{Acknowledgments}

The authors are grateful to FAPESP (process 2018/24612-9), CAPES (001), and IF Goiano for financial support (process 23218.003129.2020-81). The authors Azeredo and Ferreira thank CNPq for their Research Productivity fellowships (302381/2016-3 and 310728/2019-3, respectively).

\section{Conflict of Interest}

The authors declare that there is no conflict of interests regarding the publication of this paper

\section{Ethical approval}

This article does not contain any studies with human or animal subjects.

\section{Informed consent}

Informed consent was obtained from all individual participants included in this study.

\section{References}

1. Abdollahi M, Alboofetileh M, Rezaei M, Behrooz R (2013) Comparing physico-mechanical and thermal properties of alginate nanocomposite films reinforced with organic and/or inorganic nanofillers. Food Hydrocolloids 32:416-424

2. Alizadeh V, Barzegar H, Nasehi B, Samavati V (2017) Development of a chitosan-montmorillonite

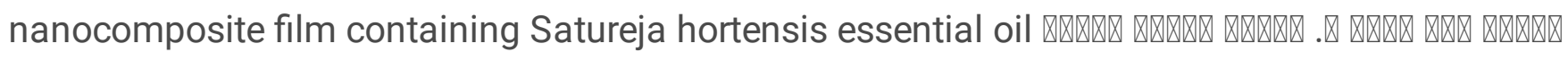
143-13:131

3. Aswathanarayan JB, Vittal RR (2019) Nanoemulsions and their potential applications in food industry. Front Sustain Food Syst 3:10.3389 
4. Atarés L, Chiralt A (2016) Essential oils as additives in biodegradable films and coatings for active food packaging. Trends Food Sci Technol 48:51-62

5. Azeredo HM, Miranda KW, Ribeiro HL, Rosa MF, Nascimento DM (2012) Nanoreinforced alginateacerola puree coatings on acerola fruits. Journal of food engineering 113:505-510

6. Campos Ad, Claro PC, Luchesi BR, Miranda M, Souza FV, Ferreira MD, Marconcini JM (2019) Curaua cellulose sheets dip coated with micro and nano carnauba. wax emulsions Cellulose 26:7983-7993

7. da Rocha Neto AC, Navarro BB, Canton L, Maraschin M, Di Piero RM (2019) Antifungal activity of palmarosa (Cymbopogon martinii), tea tree (Melaleuca alternifolia) and star anise (Illicium verum) essential oils against Penicillium expansum and their mechanisms of action LWT 105:385-392

8. Dai L, Zhang J, Cheng F (2020) Cross-linked starch-based edible coating reinforced by starch nanocrystals and its preservation effect on graded Huangguan. pears Food Chemistry 311:125891

9. de Mesquita JP, Donnici CL, Pereira FV (2010) Biobased nanocomposites from layer-by-layer assembly of cellulose nanowhiskers. with chitosan Biomacromolecules 11:473-480

10. de Souza Coelho CC, Silva RBS, Carvalho CWP, Rossi AL, Teixeira JA, Freitas-Silva O, Cabral LMC (2020) Cellulose nanocrystals from grape pomace and their use for the development of starch-based nanocomposite films International Journal of Biological Macromolecules

11. El Miri N, Abdelouahdi K, Barakat A, Zahouily M, Fihri A, Solhy A, El Achaby M (2015) Bionanocomposite films reinforced with cellulose nanocrystals: Rheology of film-forming solutions, transparency, water vapor barrier and tensile properties of films. Carbohyd Polym 129:156-167

12. Espitia PJ, Fuenmayor CA, Otoni CG (2019) Nanoemulsions: Synthesis, characterization, and application in bio-based active food packaging Comprehensive. Reviews in Food Science Food Safety 18:264-285

13. Freitas CAS, Vieira ÍGP, Sousa PHM, Muniz CR, da Costa Gonzaga ML, Guedes MIF (2016) Carnauba wax p-methoxycinnamic diesters: Characterisation, antioxidant activity and simulated gastrointestinal digestion followed by in vitro bioaccessibility. Food Chem 196:1293-1300

14. Hamdi M, Nasri R, Li S, Nasri M (2019) Bioactive composite films with chitosan and carotenoproteins extract from blue crab shells: Biological potential and structural, thermal, and mechanical characterization. Food Hydrocoll 89:802-812

15. Hubbe MA, Ferrer A, Tyagi P, Yin Y, Salas C, Pal L, Rojas OJ (2017) Nanocellulose in thin films, coatings, and plies for packaging applications. A review BioResources 12:2143-2233

16. Johar N, Ahmad I (2012) Morphological, thermal, and mechanical properties of starch biocomposite films reinforced by cellulose nanocrystals from rice husks BioResources 7:5469-5477

17. Jonoobi M, Oladi R, Davoudpour Y, Oksman K, Dufresne A, Hamzeh Y, Davoodi R (2015) Different preparation methods and properties of nanostructured cellulose from various natural resources and residues:. a review Cellulose 22:935-969

18. Jouyandeh M, Paran SMR, Jannesari A, Saeb MR (2019) 'Cure Index'for thermoset composites. Prog Org Coat 127:429-434 
19. Kavoosi G, Rahmatollahi A, Dadfar SMM, Purfard AM (2014) Effects of essential oil on the water binding capacity, physico-mechanical properties, antioxidant and antibacterial activity of gelatin films LWT-Food. Science Technology 57:556-561

20. Khan A et al (2012) Mechanical and barrier properties of nanocrystalline cellulose reinforced chitosan based nanocomposite films. Carbohydrate polymers 90:1601-1608

21. Li M, Tian X, Jin R, Li D (2018) Preparation and characterization of nanocomposite films containing starch and cellulose nanofibers. Ind Crops Prod 123:654-660

22. Ma Q, Wang $L$ (2016) Preparation of a visual $\mathrm{pH}$-sensing film based on tara gum incorporating cellulose and extracts from grape skins. Sens Actuators B 235:401-407

23. Mahcene $Z$ et al (2020) Development and characterization of sodium alginate based active edible films incorporated with essential oils of some medicinal plants. Int J Biol Macromol 145:124-132

24. Milanovic JM, Levic V, Rajic S, Nedovic N, Bugarski V, B (2010) Microencapsulation of Flavors in. Carnauba Wax Sensors 10:901-912

25. Noshirvani N, Ghanbarzadeh B, Gardrat C, Rezaei MR, Hashemi M, Le Coz C, Coma V (2017) Cinnamon and ginger essential oils to improve antifungal, physical and mechanical properties of chitosan-carboxymethyl cellulose. films Food Hydrocolloids 70:36-45

26. Noshirvani N, Hong W, Ghanbarzadeh B, Fasihi H, Montazami R (2018) Study of cellulose nanocrystal doped starch-polyvinyl alcohol bionanocomposite films. Int J Biol Macromol 107:20652074

27. Ochoa TA, Almendárez BEG, Reyes AA, Pastrana DMR, López GFG, Belloso OM, Regalado-González C (2017) Design and characterization of corn starch edible films including beeswax and natural antimicrobials. Food bioprocess technology 10:103-114

28. Oliveira Filho $\mathrm{J}$ et al (2020a) New approach in the development of edible films: the use of carnauba wax micro- or nanoemulsions in arrowroot starch-based films. Food Packaging and Shelf Life

29. Oliveira Filho J, Deus I, Valadares A, Fernandes C, Estevam E, Egea M (2020b) Chitosan Film with Citrus limonia Essential Oil: Physical and Morphological Properties and Antibacterial Activity. Colloids Interfaces 4:18

30. Oliveira Filho $\mathrm{J}$ et al (2019) Active food packaging: Alginate films with cottonseed protein hydrolysates. Food Hydrocolloids 92:267-275. doi:https://doi.org/10.1016/j.foodhyd.2019.01.052

31. Oliveira TíS et al (2017) Bionanocomposite films based on polysaccharides from banana peels. Int $J$ Biol Macromol 101:1-8

32. Pastor C, Sánchez-González L, Chiralt A, Cháfer M, González-Martínez C (2013) Physical and antioxidant properties of chitosan and methylcellulose based films containing resveratrol. Food Hydrocolloids 30:272-280

33. Pereda M, Dufresne A, Aranguren MI, Marcovich NE (2014) Polyelectrolyte films based on chitosan/olive oil and reinforced with cellulose nanocrystals. Carbohyd Polym 101:1018-1026 
34. Raigond P et al (2019) Antimicrobial activity of potato starch-based active biodegradable nanocomposite films. Potato Res 62:69-83

35. Ribeiro-Santos R, de Melo NR, Andrade M, Sanches-Silva A (2017) Potential of migration of active compounds from protein-based films with essential oils to a food and a food simulant Packaging. Technology Science 30:791-798

36. Rico M, Rodríguez-Llamazares S, Barral L, Bouza R, Montero B (2016) Processing and characterization of polyols plasticized-starch reinforced with microcrystalline cellulose. Carbohydrate polymers 149:83-93

37. Rodrigues DC, Caceres CA, Ribeiro HL, de Abreu RFA, Cunha AP, Azeredo HMC (2014) Influence of cassava starch and carnauba wax on physical properties of cashew tree gum-based films. Food Hydrocolloids 38:147-151. doi:https://doi.org/10.1016/j.foodhyd.2013.12.010

38. Salmieri S et al (2014) Antimicrobial nanocomposite films made of poly (lactic acid)-cellulose nanocrystals (PLA-CNC) in food applications-part B: effect of oregano essential oil release on the inactivation of Listeria monocytogenes in mixed vegetables Cellulose 21:4271-4285

39. Sánchez-González L, Vargas M, González-Martínez C, Chiralt A, Chafer M (2011) Use of essential oils in bioactive edible coatings: a review. Food Eng Rev 3:1-16

40. Santos TM, Pinto AMB, de Oliveira AV, Ribeiro HL, Caceres CA, Ito EN, Azeredo HMC (2014) Physical properties of cassava starch-carnauba wax emulsion films as affected by component proportions International. Journal of Food Science Technology 49:2045-2051. doi:10.1111/ijfs.12499

41. Shankar S, Reddy JP, Rhim J-W (2015) Effect of lignin on water vapor barrier, mechanical, and structural properties of agar/lignin composite films. Int J Biol Macromol 81:267-273

42. Silva APM, Oliveira AV, Pontes SM, Pereira AL, Rosa MF, Azeredo HM (2019) Mango kernel starch films as affected by starch nanocrystals and cellulose nanocrystals. Carbohydrate polymers 211:209-216

43. Sogut $E$ (2020) Active whey protein isolate films including bergamot oil emulsion stabilized by nanocellulose. Food Packaging Shelf Life 23:100430

44. Soković M, Barišić B, Sladić S (2009) Model of quality management of hard coatings on ceramic cutting tools. J Mater Process Technol 209:4207-4216

45. Song X, Zuo G, Chen F (2018) Effect of essential oil and surfactant on the physical and antimicrobial properties of corn and wheat starch films. Int J Biol Macromol 107:1302-1309. doi:https://doi.org/10.1016/j.ijbiomac.2017.09.114

46. Sousa HAdF, JGd OF, Mariana E, Silva B, ERd, Macagnan D, Pires M, Peixoto J (2019) Active film incorporated with clove essential oil on storage of banana varieties. Nutrition Food Science 49:911924. doi:10.1108/NFS-09-2018-0262

47. Syahida SN, Ismail-Fitry MR, Ainun ZMAa, Nur Hanani ZA (2020) Effects of palm wax on the physical, mechanical and water barrier properties of fish gelatin films for food packaging application. Food Packaging Shelf Life 23:100437. doi:https://doi.org/10.1016/j.fpsl.2019.100437 
48. Thakur R, Pristijono P, Scarlett CJ, Bowyer M, Singh SP, Vuong QV (2019) Starch-based films: Major factors affecting their properties International. Journal of Biological Macromolecules 132:10791089. doi:https://doi.org/10.1016/j.ijbiomac.2019.03.190

49. Thomas D, Nath MS, Mathew N, Reshmy R, Philip E, Latha M (2020) Alginate film modified with aloevera gel and cellulose nanocrystals for wound dressing application: Preparation, characterization and in vitro evaluation. Journal of Drug Delivery Science Technology 59:101894

50. Valadares ACF et al (2020) Incorporation of essential oils from Piper aduncum into films made from arrowroot starch: effects on their physochemical properties and antifungal activity. Quim Nova 43:729-737

51. Yadav MP, Hicks KB, Johnston DB, Hotchkiss AT Jr, Chau HK, Hanah K (2016) Production of biobased fiber gums from the waste streams resulting from the commercial processing of corn bran and oat hulls. Food Hydrocolloids 53:125-133

52. Zhang H, Jung J, Zhao Y (2017) Preparation and characterization of cellulose nanocrystals films incorporated with essential oil loaded $\beta$-chitosan beads. Food Hydrocolloids 69:164-172

53. Zhang Y, Simpson B, Dumont M-J (2018) Effect of beeswax and carnauba wax addition on properties of gelatin films: A comparative study. Food Bioscience 26:88-95.

doi:https://doi.org/10.1016/j.fbio.2018.09.011

54. Zhou Y, Sun S, Bei W, Zahi MR, Yuan Q, Liang H (2018) Preparation and antimicrobial activity of oregano essential oil Pickering emulsion stabilized by cellulose nanocrystals. Int J Biol Macromol 112:7-13

55. Zinoviadou KG, Koutsoumanis KP, Biliaderis CG (2009) Physico-chemical properties of whey protein isolate films containing oregano oil and their antimicrobial action against spoilage flora of fresh beef. Meat Sci 82:338-345

\section{Figures}
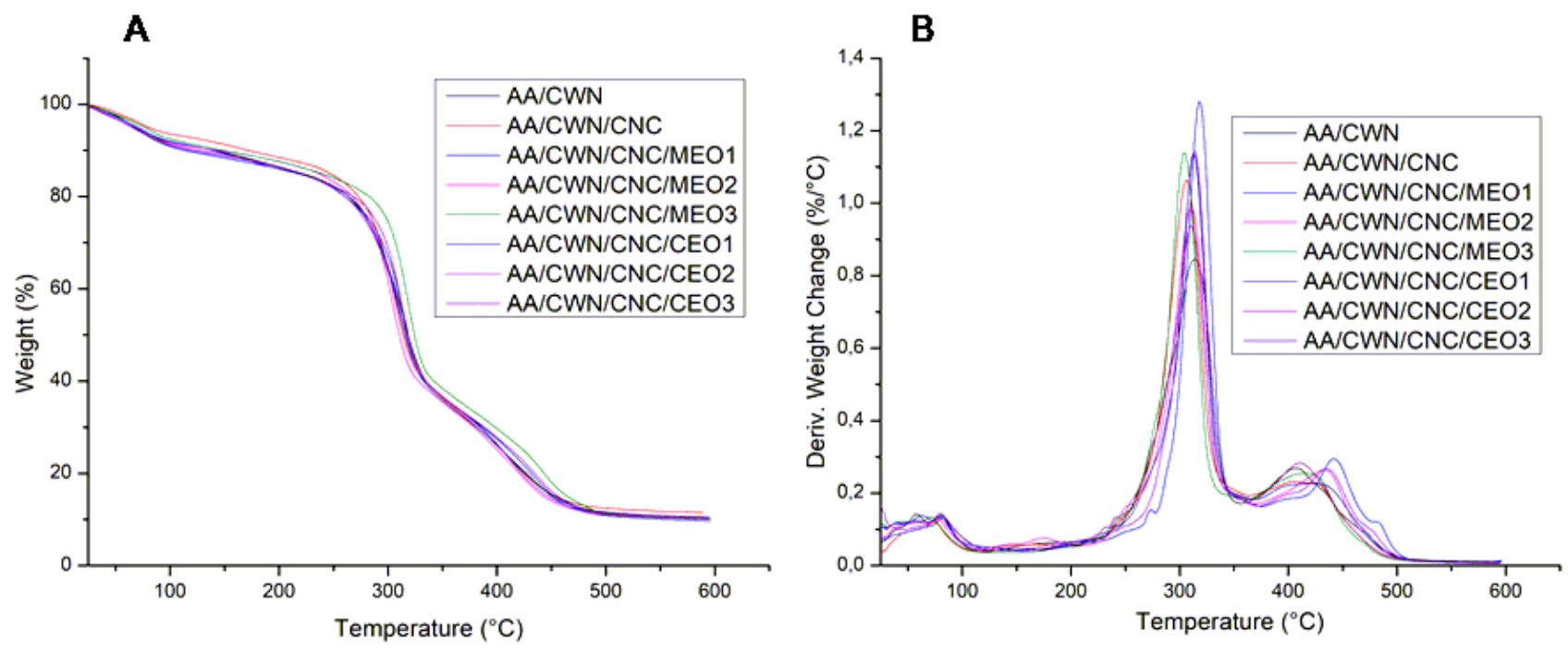


\section{Figure 1}

Thermogravimetric analysis (TGA) (A) and derivative thermogravimetry (DTG) (B) curves of arrowrootbased films (AA) with carnauba wax nanoemulsion (CWN) reinforced with cellulose nanocrystals (CNC) and supplemented with Mentha spicata and Cymbopogon martini essential oils (MEO and CEO, respectively) in concentrations of $0.1 \%$ (MEO1 or CEO1), $0.2 \%$ (MEO2 or CEO2), or $0.3 \%$ (MEO3 or CEO3)

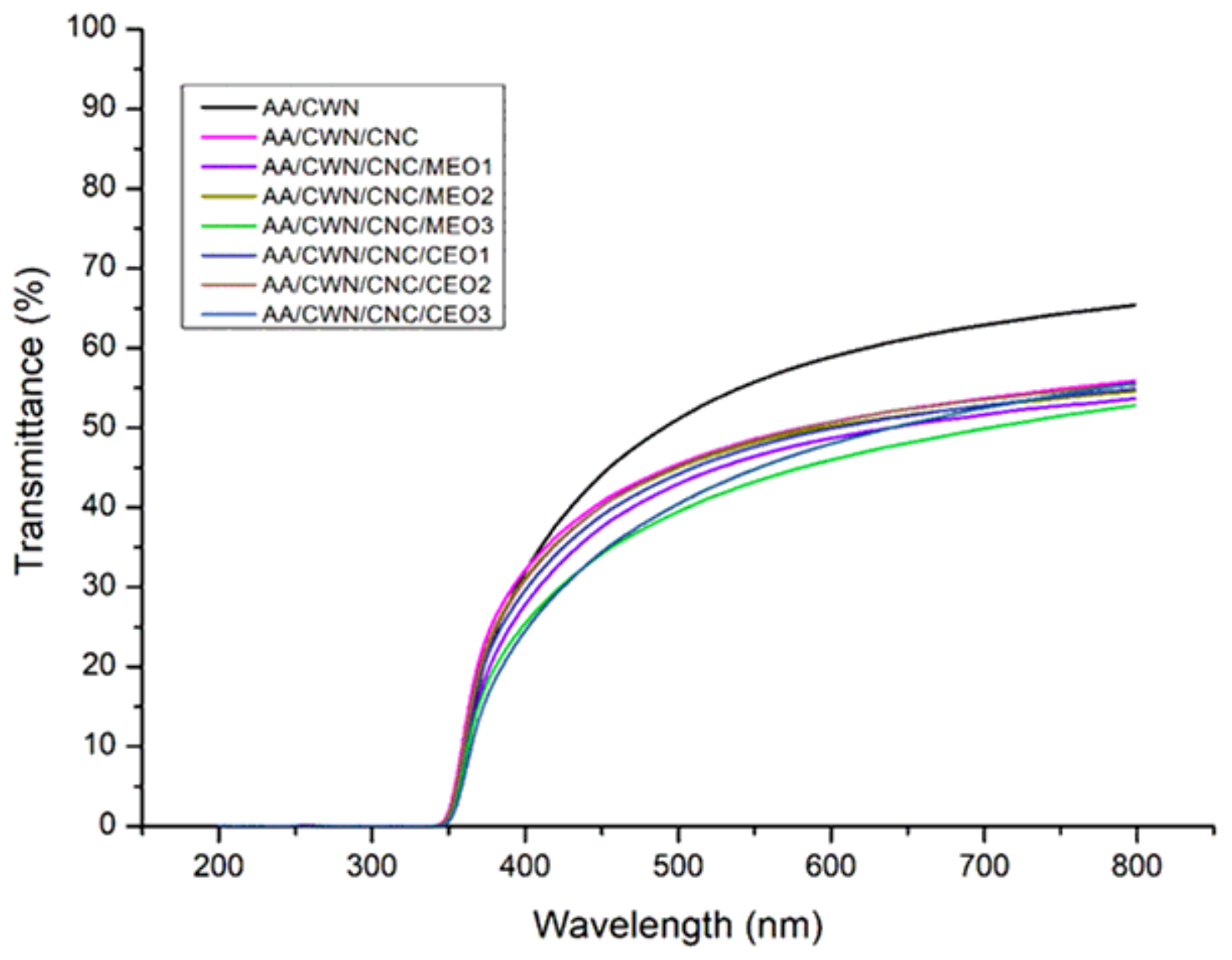

\section{Figure 2}

The light transmission rate of films. The formulation codes refer to the main components, namely: AA, arrowroot starch; CWN: carnauba wax nanoemulsion; CNC: cellulose nanocrystals; MEO1: Mentha spicata essential oil at $0.1 \%$; MEO2: Mentha spicata essential oil at $0.2 \%$; MEO3: Mentha spicata essential oil at 0.3\%; CEO1: Cymbopogon martini essential oil at 0.1\%; CEO2: Cymbopogon martini essential oil at $0.2 \%$; CEO3: Cymbopogon martini essential oil at $0.3 \%$. 


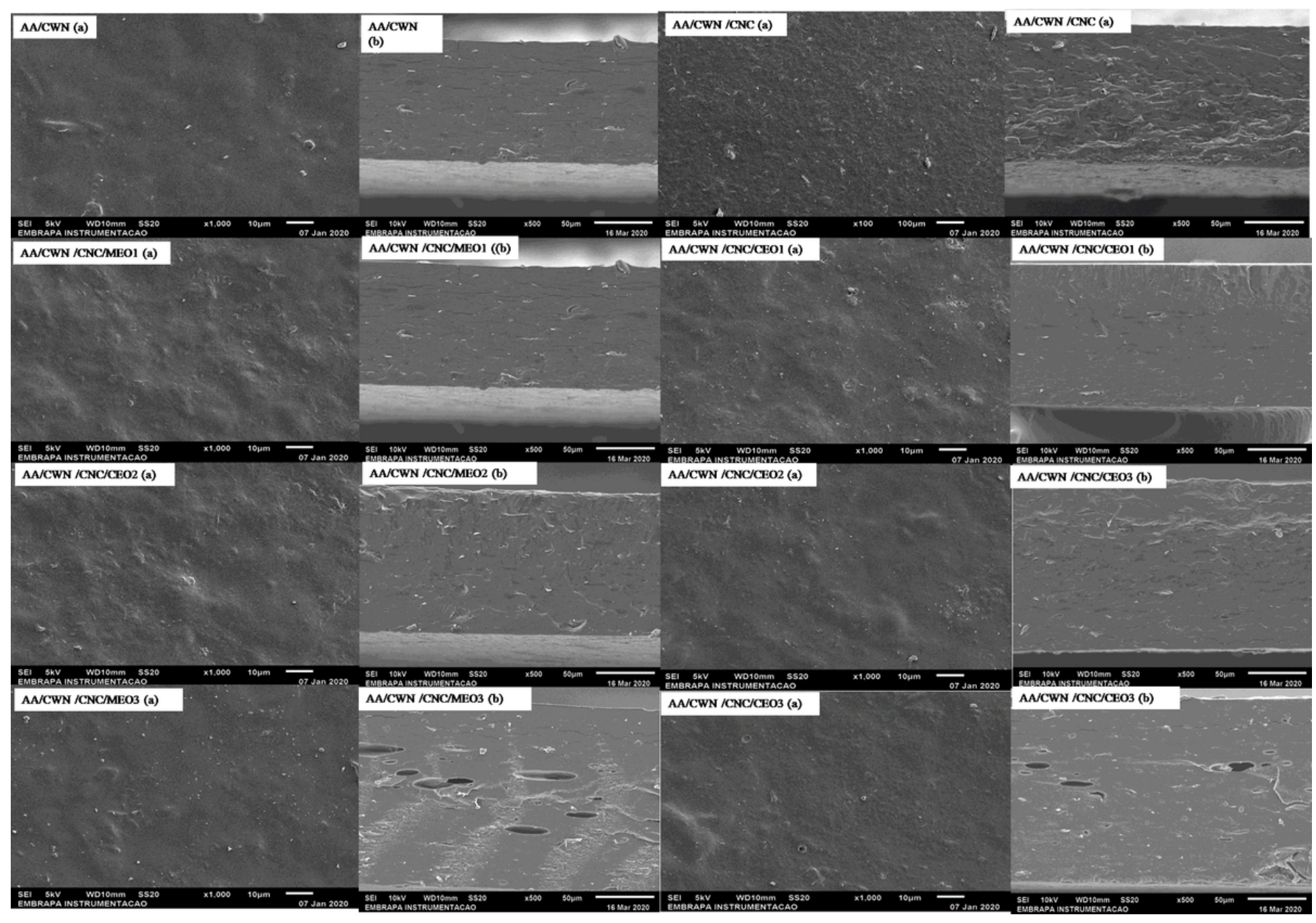

\section{Figure 3}

SEM micrographs (1000x magnification) of arrowroot-based films (AA) with carnauba wax nanoemulsion (CWN) reinforced with cellulose nanocrystals (CNC) and supplemented with Mentha spicata and Cymbopogon martini essential oils (MEO and CEO, respectively) in concentrations of $0.1 \%$ (MEO1 or CEO1), $0.2 \%$ (MEO2 or CEO2), or $0.3 \%$ (MEO3 or CEO3) 